\title{
Interferência do alumínio no crescimento radicular, absorção e acúmulo de fósforo em plantas de paricá
}

A espécie Schizolobium amazonicum Huber ex. Ducke (paricá), é uma espécie nativa plantada para a produção de madeira em larga escala. O bom desenvolvimento da espécie depende de fatores como a tolerância a níveis de alguns elementos tóxicos para as plantas, como o alumínio (Al3+), e de nutriente em concentrações adequadas, como o fósforo (P). Desta forma, o objetivo do estudo foi analisar o efeito do alumínio na absorção e translocação de fósforo e a presença desses elementos nas raízes de mudas de Schizolobium amazonicum Huber ex. Ducke cultivadas em solução nutritiva. O estudo foi realizado em casa de vegetação do Instituto de Ciências Agrárias da Universidade Federal Rural da Amazônia (Belém/PA). Os tratamentos consistiram em duas concentrações de alumínio: 0 e $20 \mathrm{mg} \mathrm{L-1}$, aplicados na solução nutritiva, composta por: $97 \mathrm{mgL}-1$ H2PO-4. Foi determinado o acúmulo de fósforo (P) e alumínio (Al) nas raízes e na parte aérea das plantas para se avaliar a influência da fitotoxidez nas plantas. Além disso, foram realizadas análises quali-quantitativas dos dois elementos nos tecidos radiculares, onde foi observada a presença e a porcentagem dos elementos na epiderme, no córtex e no cilindro central, através de análises de espectrometria de energia dispersiva (EDS). Os dados de matéria seca, acúmulo de fósforo e alumínio foram submetidos ao teste de T a 1\% de probabilidade no programa Bioestat 5.0. Também foram calculadas estatísticas descritivas (médias e porcentagens) para as variáveis da análise de espectrometria. As plantas tratadas com Al apresentaram baixa produção de matéria seca na parte aérea, enquanto na raiz observou-se grandes ganhos de matéria. O P e o Al tenderam a se acumular nas raízes, sendo pouco translocados para a parte aérea. $\mathrm{O}$ alumínio prejudicou a translocação de fósforo para a parte aérea das plantas de paricá. O P estava em maior quantidade no córtex e o alumínio na epiderme das raízes.

\section{Aluminum interference on radicular growth, absorption and phosphor accumulation in paricá plants}

\begin{abstract}
The species Schizolobium amazonicum Huber ex. Ducke (paricá) is a native species planted for large-scale timber production. The good development of the species depends on factors such as tolerance to levels of some plant toxic elements, such as aluminum (Al3+), and nutrient in appropriate concentrations, such as phosphorus (P). Thus, the objective of this study was to analyze the effect of aluminum on phosphorus absorption and translocation and the presence of these elements in the roots of Schizolobium amazonicum Huber ex. Ducke grown in nutrient solution. The study was conducted in a greenhouse of the Institute of Agrarian Sciences of the Federal Rural University of Amazonia (Belém/PA). The treatments consisted of two aluminum concentrations: 0 and $20 \mathrm{mg} \mathrm{L}-1$, applied to the nutrient solution, consisting of: $97 \mathrm{mgL}-1$ H2PO-4. Phosphorus (P) and aluminum (Al) accumulation in the roots and shoots were determined concentrations: 0 and $20 \mathrm{mg} \mathrm{L}-1$, applied to the nutrient solution, consisting of: $97 \mathrm{mgL}-1 \mathrm{H} 2 \mathrm{PO}-4$. Phosphorus (P) and aluminum (Al) accumulation in the roots and shoots were determined
to evaluate the influence of plant phytotoxicity. In addition, qualitative and quantitative analyzes of the two elements were performed in the root tissues, where the presence and percentage of the elements in the epidermis, cortex and central cylinder were observed through dispersive energy spectrometry (EDS) analyzes. The dry matter, phosphorus accumulation and aluminum data were submitted to the $\mathrm{T}$ test at $1 \%$ probability in the Bioestat 5.0 program. Descriptive statistics (means and percentages) were also calculated for the spectrometric analysis variables. The plants treated with Al presented low dry matter production in the shoot, while in the root it was observed great gains of matter. P and Al tended to accumulate in the roots, being poorly translocated to the shoot. Aluminum impaired the translocation of phosphorus to the aerial part of the paricá plants. P was more in the cortex and aluminum in the epidermis of the roots.
\end{abstract}

Keywords: Aluminum phytotoxicity; Schizolobium amazonicum; Spectrometry analysis; Root.

Topic: Ciências do Solo

Reviewed anonymously in the process of blind peer.
Received: 02/12/2019

Approved: 10/01/2020
Vanessa Leão Peleja (D)

Universidade Federal do Oeste do Pará, Brasil http://lattes.cnpq.br/4847354203016902 http://orcid.org/0000-0003-2138-3277 peleja.floresta@gmail.com

Fernanda llkiu Borges de Souza Embrapa Amazônia Oriental, Brasil http://lattes.cnpq.br/4210968979199688 fernanda.ilkiu@embrapa.br

Anna Karyne Costa Rego Universidade Federal Rural da Amazônia, Brasil http://lattes.cnpq.br/7144944987495270 http://orcid.org/0000-0002-1514-7801 anna.kcosta@gmail.com
Mario Lopes da Silva Júnior (iD

Universidade Federal Rural da Amazônia, Brasil http://lattes.cnpq.br/2220699289355930 http://orcid.org/0000-0001-9772-1290 mario.silvajunior@yahoo.com.br

Ana Catarina Siqueira Furtado

Universidade Federal Rural da Amazônia, Brasil http://lattes.cnpq.br/3857949988201584 furtadoanacatarina@gmail.com

Cristina Aledi Felsemburgh (it)

Universidade Federal do Oeste do Pará, Brasil http://lattes.cnpq.br/8446110971099607

http://orcid.org/0000-0002-8199-8639 crisalefel@gmail.com
Edgard Siza Tribuzy (D)

Universidade Federal do Oeste do Pará, Brasil http://lattes.cnpq.br/3775720692542821 http://orcid.org/0000-0002-3318-0525 estribuzy@gmail.com
Referencing this:

PELEJA, V. L.; SOUZA, F. I. B.; REGO, A. K. C.; SILVA JÚNIOR., M. L.; FURTADO, A. C. S.; FELSEMBURGH, C. A.; TRUBUZY, E. S.. Interferência do alumínio no crescimento radicular, absorção e acúmulo de fósforo em plantas de paricá. Revista Ibero Americana de Ciências Ambientais, v.11, n.1, p.1-8, 2020. DOI: http://doi.org/10.6008/CBPC2179-6858.2020.001.0001 


\section{INTRODUÇÃO}

Na região amazônica, o Schizolobium amazonicum Huber ex. Ducke, conhecido popularmente como paricá, é uma espécie nativa plantada para a produção de madeira em larga escala, que vem ganhando destaque econômico por apresentar rápido crescimento e alta produtividade, além de possuir uso diversificado (VIEIRA, 2007; CARVALHO, 2007). A indústria madeireira no Pará utiliza a espécie para fabricação chapas de compensados de alta qualidade e uniformidade, que são exportados principalmente para os Estados Unidos, conquistando a preferência dos importadores (MELO, 2013; AMATA, 2009).

O bom desenvolvimento da espécie depende de fatores como, tolerância a níveis de alguns elementos tóxicos para as plantas, como o alumínio $\left(\mathrm{Al}^{3+}\right)$, normalmente presentes nos solos da Amazônia. A maior parte deles é altamente intemperizados e ácidos, o que oportuniza a ocorrência do íon trivalente $\mathrm{Al}^{3+}$ tanto na solução do solo como em sítios de troca catiônica, prejudicando o desenvolvimento normal das plantas (HARIDASAN, 2006).

Em solos altamente intemperizados, o fósforo tende a se precipitar com o alumínio (Al-P), devido possuírem alta afinidade, formando diversos tipos de fosfatos. Além disso, o elemento pode ser adsorvido (fixado) à superfície das partículas de argila dos óxidos de alumínio, formando variscita, Al $(\mathrm{OH})_{2} \mathrm{H}_{2} \mathrm{PO}_{4}$ (CATANI et al., 1968; RESENDE et al., 2007).

Plantas submetidas a níveis tóxicos de Al, geralmente, apresentam sintomas de deficiência de fósforo, devido interações entre estes elementos no solo, na superfície e no interior das células das raízes. O fósforo é um elemento de extrema importância para os vegetais encontrado no material genético e moléculas fundamentais, componente da molécula de ATP responsável pelo fornecimento de energia em todas as funções metabólicas das plantas, desta forma, desempenha importante papel na respiração e na fotossíntese (FURLANI, 2004; TAIZ et al., 2013).

Para plantas agrícolas, geralmente, a primeira resposta a fitotoxidez de alumínio ocorre na raiz (MALAVOLTA, 2006), que inicialmente inibe a expansão e alongamento das células radiculares e, posteriormente, a divisão celular (KOCHIAN, 2003; MATSUMOTO, 2000). Segundo esses autores, também podem ocorrer injúrias na membrana plasmática, prejudicando a absorção e transporte de água e de nutrientes, como o fósforo.

Na maioria das espécies, a exposição prolongada ao Al provoca alterações morfológicas como: o engrossamento da raiz, aspecto quebradiço, desenvolvendo uma coloração castanha, além de, ficam mais curtas. Em alguns casos, esses danos não são permanentes, pois, dependendo da severidade do estresse, a taxa de crescimento poderá ter caráter reversível ou não (ROSSIELLO et al., 2006), sendo esse um indicador de plantas tolerantes.

As plantas variam em grau de fitotoxidade ao íon, com isso, a identificação do grau de toxidez das espécies tem tido grande foco em estudos (HARIDASAN, 2006). Alves et al. (2001) em estudos com cássiaverrugosa e ipê-mirim, constataram que as espécies florestais são sensíveis ao $\mathrm{Al}^{\mathrm{l}^{3+}} \mathrm{em}$ diferentes graus, pois 
as plantas de cássia apresentaram sintomas de toxicidade na concentração de $10 \mathrm{mg} \mathrm{L}^{-1}$, enquanto as plantas de ipê-mirim apresentaram apenas na concentração de $20 \mathrm{mg} \mathrm{L}^{-1}$ de alumínio.

Embora o alumínio não seja considerado elemento essencial para espécies vegetais, em baixas concentrações ele pode estimular o crescimento de algumas plantas. No crescimento de mudas de espécies arbóreas os efeitos benéficos do Al e a tolerância a este elemento são mais prováveis, já que naturalmente estas espécies se desenvolvem em solos ácidos (HARIDASAN, 2006). Devidos aos fatores mencionados, a ação do alumínio nos sistemas biológicos tem provocado bastante interesse a procura de variedades mais tolerantes ao Al, no intuito de diminuir os gastos com insumos não renováveis (BRITEZ, 2001).

A seleção da espécie, Schizolobium amazonicum Huber ex Ducke (paricá), deve-se devido a essa ser nativa da região amazônica possuir alta produtividade, qualidade de madeira e possuir uma grande importância econômica e ecológica (AMATA, 2009). Hoffmann et al. (2011), concluíram que o paricá possui características dendrométricas similares aos das espécies tradicionais dos gêneros Pinus e Eucalyptus, mostrando grande potencial para plantios comerciais na região.

Diante da importância da espécie e os malefícios do alumínio para as plantas faz-se necessário um estudo sobre o comportamento e a tolerância do paricá na presença de Al, que pode colaborar para um manejo mais adequado dos plantios. Desta forma, o objetivo do estudo foi analisar o efeito do alumínio na absorção e translocação de fósforo e a presença desses elementos nas raízes de mudas de Schizolobium amazonicum Huber ex. Ducke cultivadas em solução nutritiva.

\section{METODOLOGIA}

O estudo foi realizado em casa de vegetação do Instituto de Ciências Agrárias da Universidade Federal Rural da Amazônia (Belém/PA). Foram utilizadas sementes de paricá (Schizolobium amazonicum) que passaram por quebra de dormência com escarificação manual, seguida da imersão em água destilada em temperatura ambiente, durante um período de 12 horas. Após este período, foram semeadas em bandeja contendo areia lavada e auto clavada, sendo irrigadas com água destilada.

Após 15 dias foram selecionadas plântulas com aspecto e tamanho similar (de três folíolos e altura média $16 \mathrm{~cm} \pm 2 \mathrm{~cm}$ ), que foram transferidas para vasos plásticos com capacidade de $5 \mathrm{~L}$, preenchidos com sílica moída (tipo grosso) e solução nutritiva de Hoagland et al. (1938), composta por: $97 \mathrm{mgL}^{-1} \mathrm{H}_{2} \mathrm{PO}_{4}^{-}$. A solução foi renovada semanalmente e as perdas por evapotranspiração foram repostas diariamente com água destilada.

Os tratamentos consistiram em duas concentrações de alumínio: 0 e $20 \mathrm{mg} \mathrm{L}^{-1}$, aplicado na forma de cloreto de alumínio $\left(\mathrm{AlCl}_{3}\right)$. O pH da solução nutritiva na presença de $\mathrm{Al}$ foi mantido em 4,8 $\pm 0,2$ e o controle em $5,5 \pm 0,2$, sendo ajustado a cada dois dias com HCl 0,1 $\mathrm{mol} \mathrm{L}^{-1}$ e $\mathrm{NaOH} 1 \mathrm{M}$. Após 45 dias de exposição ao alumínio, plantas foram seccionadas no colo separando-se a parte aérea do sistema radicular, que passaram por lavagem com água destilada e foram secos em estufa com circulação forçada de ar a $60^{\circ} \mathrm{C}$ até peso constante para a obtenção de matéria seca. 
As amostras foram levadas ao Laboratório de Química de Solos da Embrapa Amazônia Oriental CPATU, Belém/PA, para a determinação do teor de fósforo (P) e alumínio nas raízes e na parte aérea. $O$ acúmulo dos elementos nas plantas foi calculado se multiplicando os teores do elemento $\left(\mathrm{g} \mathrm{kg}^{-1}\right.$ de matéria seca), pelos valores de matéria seca da parte aérea e da raiz, dividindo-se o produto por 1000 .

No Laboratório de Microanálises do Instituto de Geociências (IG) da UFPA, foram realizadas análises quali-quantitativas de $\mathrm{P}$ e Al nos tecidos radiculares, por espectrometria de energia dispersiva (EDS, IXRF modelo Sedona-SD) acoplado ao microscópio eletrônico de varredura (MEV Zeiss, modelo SIGMA-VP). As condições de operação foram: corrente do feixe de elétrons $=80 \mu \mathrm{A}$, voltagem de aceleração constante $=20$ $\mathrm{kV}$, distância de trabalho $=8,5 \mathrm{~mm}$, tempo de contagem para análise dos elementos $=30 \mathrm{~s}$.

Para análise de espectrometria, as amostras foram preparadas no laboratório de Botânica da Empresa Brasileira de Pesquisa na Amazônia Oriental (EMBRAPA). As raízes foram lavadas com água destilada e, em seguida, desidratadas em série etanólica crescente de 10 até $100 \%$, sendo armazenadas em álcool 100\% (OLIVEIRA, 2015). As amostras foram seccionadas transversalmente e processadas em ponto crítico de $\mathrm{CO}_{2}$, montadas em suportes metálicos (stubs) através de fita de carbono dupla face e metalizadas com camada de ouro. Foram analisadas cinco amostras de cada tratamento e obtidos os dados de 30 pontos de cada amostra, divididos entre epiderme, córtex e cilindro central, para a determinação do alumínio e fósforo (Figura 1).

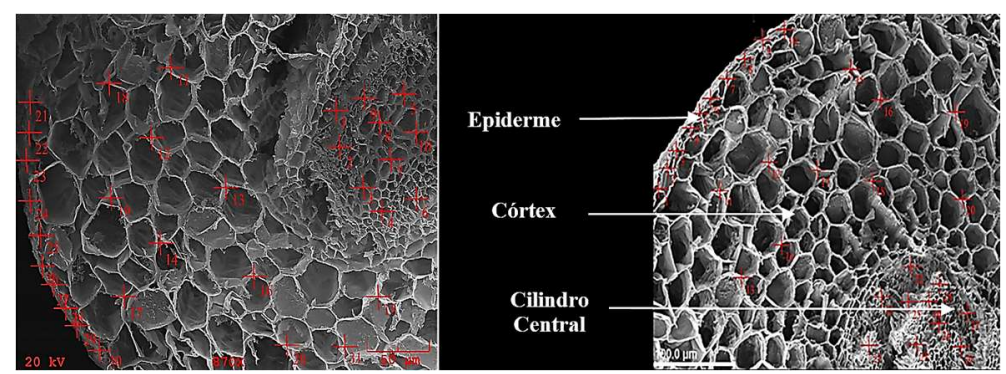

Figura 1: Corte transversal de raízes de Schizolobium amazonicum e pontos marcados para a leitura em EDS (Energy Dispersive X-ray Detector). (A) $0 \mathrm{mg} \mathrm{L}^{-1}$ de Al; (B) $20 \mathrm{mg} \mathrm{L}^{-1}$ de Al.

Os dados de matéria seca, acúmulo de fósforo e alumínio foram submetidos ao teste de T a $1 \%$ de probabilidade no programa Bioestat 5.0. Também foram calculadas estatísticas descritivas (médias e porcentagens) para as variáveis da análise de espectrometria.

\section{RESULTADOS E DISCUSSÃO}

Na ausência de alumínio as raízes se apresentaram visualmente longas e finas e de coloração mais escura, enquanto na presença do metal apresentaram um ligeiro engrossamento, poucas raízes secundárias, coloração castanho claro, aspecto quebradiço, porém não foi observado redução do crescimento (Figura 2). Segundo Grabski et al. (1995), pode ocorrer o enrijecimento da rede de filamentos de actina, provocado pelo metal, que também pode interferir na divisão celular, contribuindo para a ocorrência do engrossamento, observado no material objeto desse estudo. 

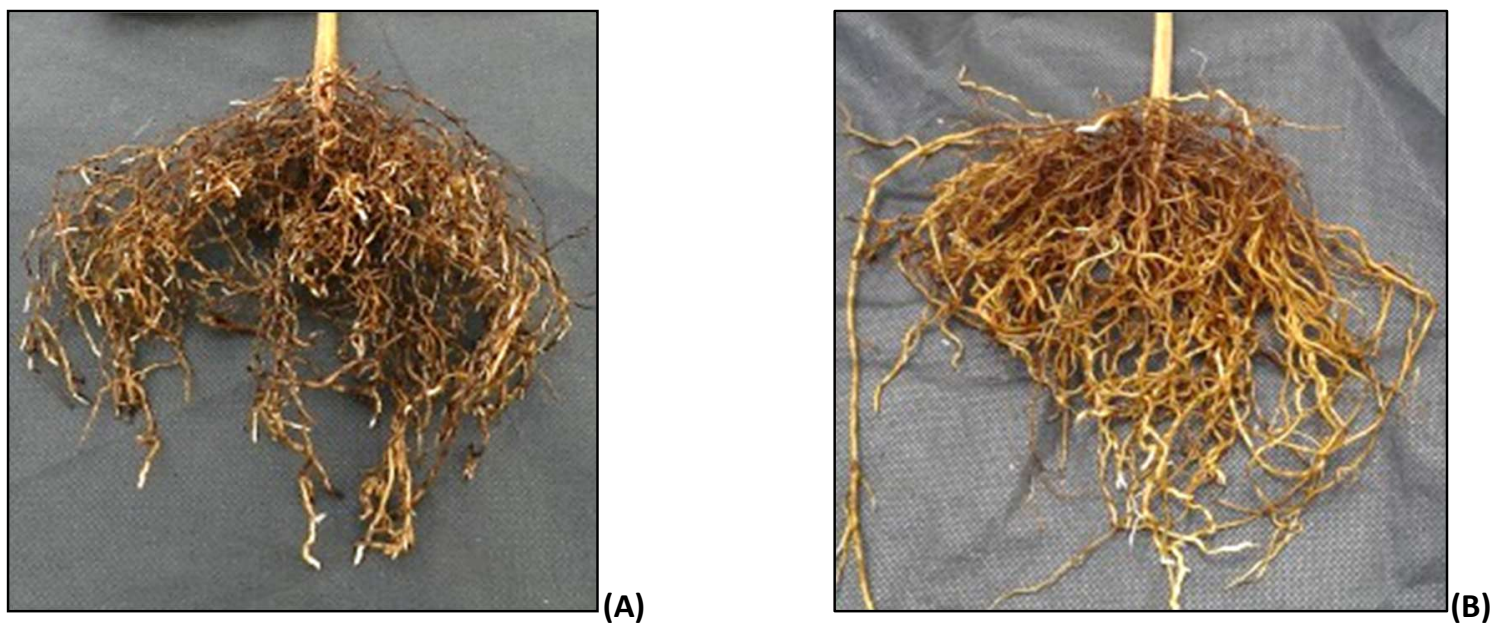

Figura 2: Raízes de Schizolobium amazonicum. (A) 0 mg L-1 de Al e (B) 20 mg L-1 de Al.

A produção de matéria seca e o acúmulo de $\mathrm{P}, \mathrm{Al}$ das na parte aérea e nas raízes das plantas de paricá apresentaram diferença em resposta ao alumínio adicionado na solução nutritiva. As plantas expostas a fitotoxidez de Al apresentaram baixa produção de matéria seca na parte aérea, enquanto na raiz se observou grandes ganhos de matéria seca, quando comparadas com o controle (Tabela 1).

Os teores de $\mathrm{P}$ aumentaram significativamente no sistema radicular das plantas tratadas com Al, quando comparadas com a parte aérea, tendendo a se acumular nas raízes, sendo pouco translocados para a parte aérea. Nas plantas controle se observa comportamento oposto, grande acúmulo do $\mathrm{P}$ na parte aérea, indicando que o elemento foi absorvido e translocado normalmente para a parte aérea. Os resultados também mostram que o Al tendeu a se acumular nas raízes sendo pouco transportado para a parte aérea.

Tabela 1: Médias do peso da matéria seca e acúmulo de fósforo ( $\mathrm{P}$ ) e alumínio (Al) na parte aérea e nas raízes de mudas de Schizolobium amazonicum.

\begin{tabular}{|c|c|c|c|c|}
\hline Tratamentos & P raiz & $P$ aérea & Al aérea & MS aérea \\
\hline & \multicolumn{2}{|c|}{ - - - g planta-1 . . - } & - - - g g planta-11 - . - & $\ldots-\ldots$ (g) $\ldots$ \\
\hline $0 \mathrm{mg} \mathrm{L}^{-1}$ de $\mathrm{Al}^{3+}$ & $0.0029 *$ & $0.0083^{*}$ & $\begin{array}{ll}-- & -- \\
\end{array}$ & $2,4^{*} \quad 1,0 *$ \\
\hline $20 \mathrm{mg} \mathrm{L}^{-1}$ de $\mathrm{Al}^{3+}$ & $0.0079 *$ & $0.0037^{*}$ & $0.0074 *$ & $2,0^{*}$ \\
\hline
\end{tabular}

* significativo $(p<0,05)$ pelo Teste T.

A baixa produção de matéria seca na parte aérea e a alta da raiz podem ser atribuídas ao efeito significativo do Al na absorção e translocação de $\mathrm{P}$. O menor conteúdo translocado de $\mathrm{P}$ reduz a taxa fotossintética e, consequentemente, a produção de biomassa (FURLANI, 2004). A baixa disponibilidade de fósforo afeta a fotossíntese, pela redução de trioses fosfato usadas durante a regeneração da ribulose 1,5 bisfosfato (RuBP) e devido a diminuição do consumo e produção de ATP e NADPH (WARREN, 2011).

Em baixas concentrações do elemento ou deficiência, algumas plantas desenvolvem mecanismos para tentar acessar o fósforo no solo, como o aumento da densidade radicular. Este incremento aumenta a habilidade da planta em acessar e absorver o $\mathrm{P}$, que quando em contato com este nutriente, tendem a acumulá-lo nos tecidos radiculares (GRANT et al., 2001). Este pode ser um dos fatores que podem ter levado ao incremento de biomassa do sistema radicular das plantas de paricá. $\mathrm{O}$ crescimento radicular em plantas expostas ao Al, também tem sido amplamente utilizado como indicador de tolerância ao Al (MATTIELLO et al., 2008), entretanto este fator deve ser avaliado com cautela. 
Benedett et al. (2017), avaliaram a tolerância de erva-mate (llex paraguariensis St. Hil.) ao Al por meio da medição do crescimento, e comentaram que raízes mais grossas são menos eficientes na absorção de nutrientes do que as mais finas. Os mesmos autores enfocam que apesar de terem observado maior crescimento radicular em maiores doses de Al, esse fato não significa que a erva não necessite de reposição nutricional. Desta forma, pode-se inferir que o desenvolvimento do sistema radicular do paricá como forma de adaptação não foi o suficiente para garantir o bom desenvolvimento das plantas.

O acúmulo de fósforo e alumínio nas raízes, geralmente ocorre devido a formação de complexos P$\mathrm{Al}$, que precipita o $\mathrm{P}$ em formas menos disponíveis nos tecidos da raiz, o que reduz sua translocação para a parte aérea (CHEN et al., 2012). A interação entre esses dois elementos ocorre no solo e continuam na superfície e no interior das células das raízes, resultando na formação de complexos e compostos pouco solúveis como o $\mathrm{Al}_{4}\left(\mathrm{PO}_{4}\right)_{3}$ na parede celular, reduzindo a disponibilidade, absorção e translocação do alumínio e do fósforo (ZHENG et al., 2005).

$\mathrm{O}$ acúmulo de $\mathrm{Al}$ nas raízes também pode ocorrer devido à forte ligação do elemento com os constituintes da pectina, na parede celular. O alumínio pode deslocar o cálcio do apoplasto por competição ou por reduzir a diferença de potencial negativo na superfície da membrana. A membrana plasmática é estabilizada por íons Ca que se ligam a proteínas e resíduos de pectina carregados negativamente na parede celular. Essas cargas negativas tornam as pectinas um grande local de ligação do Al (RENGEL, 1992; VAZQUEZ et al., 1999; HORST et al., 1999).

Com as microanálises espectrométricas de raios-X por dispersão de energia (EDS) se pôde observar que a maioria do alumínio (43\%) encontrado nas raízes segue uma tendência a ficar localizado na epiderme, diminuindo conforme a proximidade com o cilindro vascular. Nas plantas tratadas com alumínio, as maiores quantidades de fósforo foram detectadas no córtex das raízes, enquanto, nas plantas controle observa-se maior atividade de fósforo na epiderme das raízes diminuindo no sentido cilindro central (Tabela 2). Essa diminuição pode ser devido ao elemento está sendo absorvido e imediatamente translocado para a parte aérea, enquanto nas expostas a fitotóxidez o $\mathrm{P}$ tende a ficar precipitado no córtex.

Tabela 2: Valores percentuais médios de alumínio (Al) e fósforo (P) na epiderme, córtex e cilindro central das raízes de Schizolobium amazonicum em EDS.

\begin{tabular}{|c|c|c|c|c|c|}
\hline \multirow[t]{2}{*}{ Tratamentos } & Epiderme (\%) & \multicolumn{2}{|c|}{ Córtex (\%) } & \multicolumn{2}{|c|}{ Cilindro Central (\%) } \\
\hline & Al $\quad P$ & Al & $\mathbf{P}$ & $\mathrm{Al}$ & $\mathbf{P}$ \\
\hline $0 \mathrm{mg} \mathrm{L}^{-1} \mathrm{de} \mathrm{Al}^{3+}$ & $0,001 \quad 2.28$ & 0,003 & 1.81 & 0,00 & 1.51 \\
\hline $20 \mathrm{mg} \mathrm{L}^{-1}$ de $\mathrm{Al}^{3+}$ & $0,575 \quad 1.746$ & 0,393 & 2.64 & 0,298 & 2.11 \\
\hline
\end{tabular}

A alta quantidade de alumínio na epiderme pode ter ocorrido devido as raízes serem o primeiro local afetado pelo elemento, por estar em contato direto com o solo (RENGEL, 1992), neste estudo na solução nutritiva. Outra possibilidade, é que o alumínio pode ter sido precipitado através da ação de ácidos orgânicos que formam complexos estáveis (quelação), impedindo sua absorção, evitando a interação com componentes celulares ou até a penetração via simplasto (citosol) nos tecidos radiculares (MIGUEL et al., 2010; BRACCINI et al., 2000). 
A toxidade do alumínio também pode ser resultado de interações complexas das vias apoplasto (parede celular e membrana plasmática) (KOCHIAN et al., 2005). O transporte do elemento até as células corticais pode passar pela parede celular cortical via apoplasto e entrar no esteio via plasmalema até a endoderme. A endoderme representa uma barreira para o transporte do alumínio via apoplasma, visto que as estrias de Caspary, hidrófobas, não permitem a passagem de íons (RENGEL, 1992). Em teoria, este fato pode ter diminuído a ascensão do alumínio para o cilindro central evitando seu transporte para a parte aérea.

A distribuição celular de alumínio entre apoplasma e simplasma ainda é controvérsia, diferindo de uma espécie para a outra e variando conforme o grau de tolerância de cada espécie (KOCHIAN et al., 2003; ROSSIELLO et a., 2006). Para a melhor identificação do grau de tolerância do paricá é indicado o uso de outras técnicas em conjunto com a espectrometria de raios- $X$, para o melhor entendimento da dinâmica do elemento.

\section{CONCLUSÕES}

O alumínio prejudica a translocação de fósforo para a parte aérea e se acumula nas raízes em plantas de paricá. As análises de espectrometria de raios-X mostram que o fósforo está mais presente no córtex e o alumínio na epiderme das raízes.

\section{REFERÊNCIAS}

ALVES, R. M. M.; OLIVEIRA, L. E. M.; FURTINI NETO, A. E.; DELÚ FILHO, N.. Comportamento diferencial das espécies florestais cássia-verrugosa (Senna multijuga (L.C. Rich.) I. \& B.) e ipê-mirim (Tecoma stans H.B.K.) na presença de alumínio. Ciência e Agrotecnologia, Lavras, v.25, p.1161$1168,2001$.

AMATA. Revisão sobre paricá: Schizolobium amazonicum Huber ex. Ducke. São Paulo: AMATA, 2009.

BRACCINI, M. C. L.; MARTINEZ, H. E. P.; SILVA, E. A. M.; BRACCINI, A. L.; SCAPIM, C. A.. Crescimento da planta e coloração das raízes com hematoxilina como critérios de avaliação de genótipos de café quanto à tolerância à toxidez de alumínio. Revista Brasileira Ciência Solo, v.24, p.59-68, 2000.

BENEDETTI, E. L.; SANTIN, D.; BARROS, N. F.; PEREIRA, G. L.; MARTINEZ, H. P.; NEVES, J. C. L.. Alumínio estimula o crescimento radicular de erva-mate?. Pesquisa Florestal Brasileira, Colombo, v.37, n.90, p.139-147, 2017.

BRITEZ, R. M.. Efeito do alumínio em duas espécies arbóreas da Planície Litorânea da Ilha do Mel, PR. Tese (Doutorado em Engenharia Florestal) - Universidade Federal do Paraná, Curitiba, 2001.

CARVALHO, P. E. R.. Paricá: Schizolobium amazonicum. Colombo: Embrapa Florestas, 2007.

CATANI, R. A.; BATAGLIA, O. C.. Formas de ocorrência de fósforo no solo Latossólico Roxo. An. Esc. Super. Agric. Luiz de Queiroz, Piracicaba, v.25, p.99-119, 1968.
CHEN, R. F.; ZHANG, F. L.; ZHANG, Q. M.; SUN, Q. B.; DONGA, $X$. Y.; SHENA, R. F.. Aluminium-phosphorus interactions in plants growing on acid soils: Does phosphorus always alleviate aluminium toxicity?. Journal of the Science of Food and Agriculture, v.92, n.5, p.995-1000, 2012.

FURLANI, A. M. C.. Nutrição Mineral. In: KERBAUY, G. B.. Fisiologia Vegetal. Rio de Janeiro: Guanabara Koogan, 2004.

GRABSKI, S.; SCHINDLER, M.. Aluminum induces Rigor within the Actin Network of Soybean Cells. Plant Physiol, v.108, p.897-901, 1995

GRANT, C. A.; FLATEN, D. N.; TOMASIEWICZ, D. J.; SHEPPARD, S. C.. A importância do fósforo no desenvolvimento inicial da planta. Informações Agronômicas, n.95, 2001.

HARIDASAN, M.. Alumínio é um elemento tóxico para as plantas nativas do cerrado?. In: PRADO, C. H. B. A; CASALI, C. A.. Fisiologia Vegetal: práticas em relações hídricas, fotossíntese e nutrição mineral. Barueri: Manole, 2006. p.110.

HOAGLAND, D. R.; ARNON, D. I.. The water culture method for growing plants without soils. Circular 347. Berkeley: University of California, 1938.

HOFFMANN, R. G.; SILVA, G. F.; CHICHORRO, J. F.; FERREIRA, R. L. C.; VESCOVI, L. B.; ZANETI, L. Z.. Caracterização dendrométrica de plantios de paricá (Schizolobium amazonicum Huber ex. Ducke) na região de Paragominas, PA. Revista Brasileira de Ciências Agrárias, Recife, v.6, n.4, p.675-684, 2011. 
HORST, W. J.; SCHMOHL, N.; KOLLMEIER, M.; BALU KA, F.; SIVAGURU, M.. Does aluminium affect root growth of maize through interaction with the cell wall-plasma membranecytoskeleton continuum?. Plant and Soil, v.215, n.2, p.163174, 1999.

KOCHIAN, L. V.. Cellular Mechanisms of Aluminum Toxicity and Resistance in Plants. Annual Review of Plant Biology, v.46, n.1, p.237-260, 2003.

KOCHIAN, L. V.; PIÑEROS, M. A.; HOEKENGA, O. A.. The physiology, genetics and molecular biology of plant aluminum resistance and toxicity. Plant and Soil, v.274, n.12, p.175-195, 2005

MALAVOLTA, E.. Manual de nutrição mineral de plantas. São Paulo: Ceres, 2006.

MATTIELLO, E. M.; PEREIRA, M. G.; ZONTA, E.; MAURI, J.; MATIELLO, J. D.; MEIRELES, P. G.; SILVA, I. R.. Produção de matéria seca, crescimento radicular e absorção de cálcio, fósforo e alumínio Porcoffea canephora e Coffea arabica sob influência da atividade do alumínio em solução. Revista Brasileira Ciência do Solo, Viçosa, v.32, n.1, 2008.

MATSUMOTO, H.. Cell biology of aluminum toxicity and tolerance in higher plants. International Review Cytology, San Diego, v.200, p.1-46, 2000.

MELO, R. R.; DEL MENEZZI, C. H. S.; SOUZA, M. R.; STANGERLIN, D. M.. Avaliação das propriedades físicas, químicas, mecânicas e de superfície de lâminas de paricá (Schizolobium amazonicum Huber ex. Ducke). Floresta e Ambiente, v.20, n.2, p.238-249, 2013.

MIGUEL, P. S. B.; GOMES, F. T.; ROCHA, W. S. D.; MARTINS, C. E.; CARVALHO, C. A.; OLIVEIRA, A. V.. Efeitos tóxicos do alumínio no crescimento das plantas: mecanismos de tolerância, sintomas, efeitos fisiológicos, bioquímicos e controles genéticos. CES Revista, Juiz de Fora, v.24, p.13-29, 2010.
OLIVEIRA, D. M.. Técnicas de preparação de material vegetal para estudo anatômico. Belém: Instituto de Ciências Biológicas, 2015.

RENGEL, Z.. Role of calcium in aluminum toxicity. New Phytol, Camberra, v.121, p.499-513, 1992.

RESENDE, A. V.; FURTINI NETO, A. E.. Aspectos relacionados ao manejo da adubação fosfatada em solos do cerrado. Planaltina: Embrapa Cerrados, 2007.

ROSSIELLO, R. P.; NETTO, J. J.. Toxidez de Alumínio em Plantas: Novos enfoques para um velho problema. In: FERNANDES, M. S.. Nutrição Mineral de Plantas. Sociedade Brasileira de Ciências Solos, 2006. p.377-418.

TAIZ, L.; ZEIGER, E. A.. Fisiologia Vegetal. 5 ed. Porto Alegre: Artemed, 2013.

VÁZQUEZ, M. D.; POSCHENRIEDER, C.; CORRALES, I. I.; BARCELO, J.. Change in apoplastic aluminum during the initial growth response to aluminum by roots of a tolerant maize variety. Plant Physiology, v.119, p.435-444, 1999.

VIEIRA, A. H.. Sistema de produção de bandara para o Estado de Rondônia. Sistemas de Produção. Porto Velho: Embrapa Rondônia, 2007.

WARREN, C. R.. How does P affect photosynthesis and metabolite profiles of Eucalyptus globulus?. Tree Physiology, v.31, n.7, p.727-739, 2011.

ZHENG, S. J.; YANG, J. I.; FENG HE, Y.; HUI YU, X.; ZHANG, L.; FENG YOU, J.; SHEN, R. F.; MATSUMOTO, H.. Immobilization of aluminum with phosphorus in roots is associated with high aluminum resistance in buckwheat. Plant physiology, v.138, n.1, p.297-303, 2005

A CBPC - Companhia Brasileira de Produção Científica (CNPJ: 11.221.422/0001-03) detém os direitos materiais desta publicação. Os direitos referem-se à publicação do trabalho em qualquer parte do mundo, incluindo os direitos às renovações, expansões e disseminações da contribuição, bem como outros direitos subsidiários. Todos os trabalhos publicados eletronicamente poderão posteriormente ser publicados em coletâneas impressas sob coordenação da Sustenere Publishing, da Companhia Brasileira de Produção Científica e seus parceiros autorizados. Os (as) autores (as) preservam os direitos autorais, mas não têm permissão para a publicação da contribuição em outro meio, impresso ou digital, em português ou em tradução. 